\title{
Rumbling in the benthos: acoustic ecology of the California mantis shrimp Hemisquilla californiensis
}

\author{
E. R. Staaterman ${ }^{1,6, *}$, C. W. Clark ${ }^{2}$, A. J. Gallagher ${ }^{3,4,6, * *}$, M. S. deVries ${ }^{5, * *}$, \\ T. Claverie ${ }^{1, * *}$, S. N. Patek ${ }^{1}$
${ }^{1}$ Biology Department, University of Massachusetts, Amherst, Massachusetts 01003, USA
${ }^{2}$ Bioacoustics Research Program, Cornell Laboratory of Ornithology, Ithaca, New York 14850, USA
${ }^{3}$ Leonard and Jayne Abess Center for Ecosystem Science and Policy, University of Miami, Florida 33124, USA
${ }^{4}$ RJ Dunlap Marine Conservation Program, University of Miami, Florida 33149, USA
${ }^{5}$ Department of Integrative Biology, University of California, Berkeley, California 94720, USA \\ ${ }^{6}$ Present address: Rosenstiel School of Marine and Atmospheric Sciences, University of Miami, Florida 33149, USA
}

\begin{abstract}
Although much research has focused on acoustic mapping and exploration of the benthic environment, little is known about the acoustic ecology of benthic organisms, particularly benthic crustaceans. Through the use of a coupled audio-video system, a hydrophone array, and an autonomous recording unit, we tested several hypotheses about the field acoustics of a benthic marine crustacean, Hemisquilla californiensis. Living in muddy burrows in southern California, these large mantis shrimp produce low frequency 'rumbles' through muscle vibrations. First, we tested whether acoustic signals are similar in the field and in the laboratory, and discovered that field-produced rumbles are more acoustically and temporally variable than laboratory rumbles, and are typically produced in rhythmic series called 'rumble groups.' Second, we verified if the sounds were indeed coming from mantis shrimp burrows and explored whether rumble groups were produced by multiple individuals. Our results suggest that during certain time periods, multiple mantis shrimp in the vicinity of the hydrophone produce sounds. Third, we examined the relationship between behavioral and acoustic activity, and found that $H$. californiensis is most active during crepuscular periods. While these crustaceans make a substantial contribution to the benthic soundscape, omnipresent and acoustically overlapping boat noise may threaten their acoustic ecology.
\end{abstract}

KEY WORDS: Acoustic ecology · Autonomous recording unit $\cdot$ Benthic $\cdot$ Crustacean

Resale or republication not permitted without written consent of the publisher

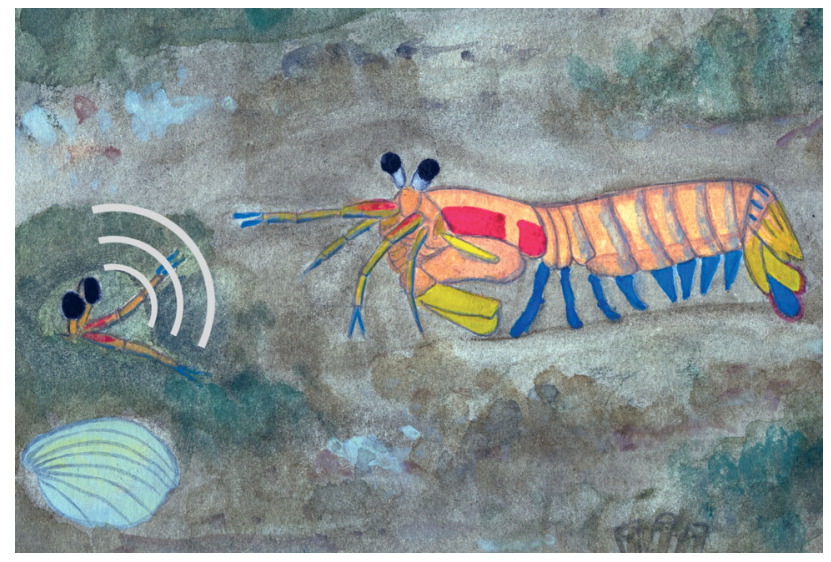

The California mantis shrimp communicates acoustically by producing low-frequency 'rumbles'.

Watercolor: E. R. Staaterman

\section{INTRODUCTION}

The acoustic soundscape of the benthic zone is a cacophony of snaps, squeaks, hums, grunts, and rasps produced by animals such as snapping shrimp (Au \& Banks 1998), clawed lobsters (Henninger \& Watson 2005), spiny lobsters (Patek \& Oakley 2003), hermit crabs (Dumortier 1963), and fishes (Tavolga 1977). Given the low-light environment in which most benthic organisms live, the acoustic modality can play important roles-attracting mates, repelling rivals, deterring predators, or maintaining territories. Moreover, daily patterns in the acoustic activity of fishes 
(McCauley \& Cato 2000, Locascio \& Mann 2008), snapping shrimp (Lammers et al. 2008), and sea urchins (Radford et al. 2008) suggest that the benthic zone is an acoustic environment with distinct diel trends. However, compared to the extensive literature on acoustic behaviors in other marine taxa such as cetaceans, few investigations have explored acoustic communication among benthic invertebrates, particularly benthic crustaceans.

Mantis shrimp (Crustacea, Stomatopoda) are benthic marine crustaceans that are well known for their fierce predatory strikes (Patek et al. 2004) and excellent visual systems (Cronin \& Marshall 2004). When the raptorial appendage of this animal makes contact with a prey item or the substrate, a sound is produced (Alcock 1900, Kemp 1913, Hazlett \& Winn 1962, Caldwell 1979, Patek \& Caldwell 2005), and stridulation may occur between the uropod and the telson (Brooks 1886, Giesbrecht 1910, Balss 1921, Dumortier 1963). The only record we could find of mantis shrimp sounds in the field is an anecdotal report of 'groaning' noises emanating from burrows of a large temperate stomatopod, the California mantis shrimp Hemisquilla californiensis (Haderlie et al. 1980).

Hemisquilla californiensis was the focus of the first comprehensive laboratory study of mantis shrimp sounds, which were referred to as 'rumbles' (Patek \& Caldwell 2006). Individuals were held in tanks, and sounds were recorded from $50 \%$ of the males $(n=12)$, and none of the females $(n=6)$. Whether or not females are capable of generating rumbles remains unknown. Rumbles appeared to be produced by vibrations of posterior mandibular remoter muscles located underneath the carapace (Fig. 1). Most rumbles lasted $<2 \mathrm{~s}$ and the mean dominant frequency was $45 \mathrm{~Hz}( \pm 10 \mathrm{SD}$, $\mathrm{n}=53$ rumbles).
While previous experiments have focused on either laboratory based sound production or the general ecology of Hemisquilla californiensis, the present study is, to our knowledge, the first to investigate the acoustics of this species in its natural habitat. $H$. californiensis occurs off the coast of California and Mexico and lives in self-constructed muddy burrows, which provide a safe place for feeding, mating, and molting (Basch \& Engle 1993). During the mating season (March to June), which is the time period of the present study, pairs of males and females reside together for several weeks. Males guard their burrows intensely, especially during crepuscular periods, when individuals are most active. $H$. californiensis typically closes its burrow with a mucous cap during periods of bright daylight and at night, presumably for protection from predators, which range from octopus to benthic-feeding elasmobranchs (Basch \& Engle 1989, Basch \& Engle 1993, Gray et al. 1997). We addressed 3 main questions: (1) Do rumbles in the field differ from those produced in the laboratory? (2) Are rumble groups produced by multiple individuals? (3) Do patterns of acoustic activity match previously documented patterns of behavioral activity?

\section{MATERIALS AND METHODS}

We utilized 3 approaches. (1) We used 2 recording systems to identify and characterize rumbles produced in the natural habitat of Hemisquilla californiensis. (2) A hydrophone array allowed us to calculate the locations of rumbles. (3) An autonomous recording unit provided acoustic data that were used to describe diel patterns of mantis shrimp acoustic activity. Field recordings were obtained at 2 locations along the coast of Santa Catalina Island, CA, USA, in the early mating
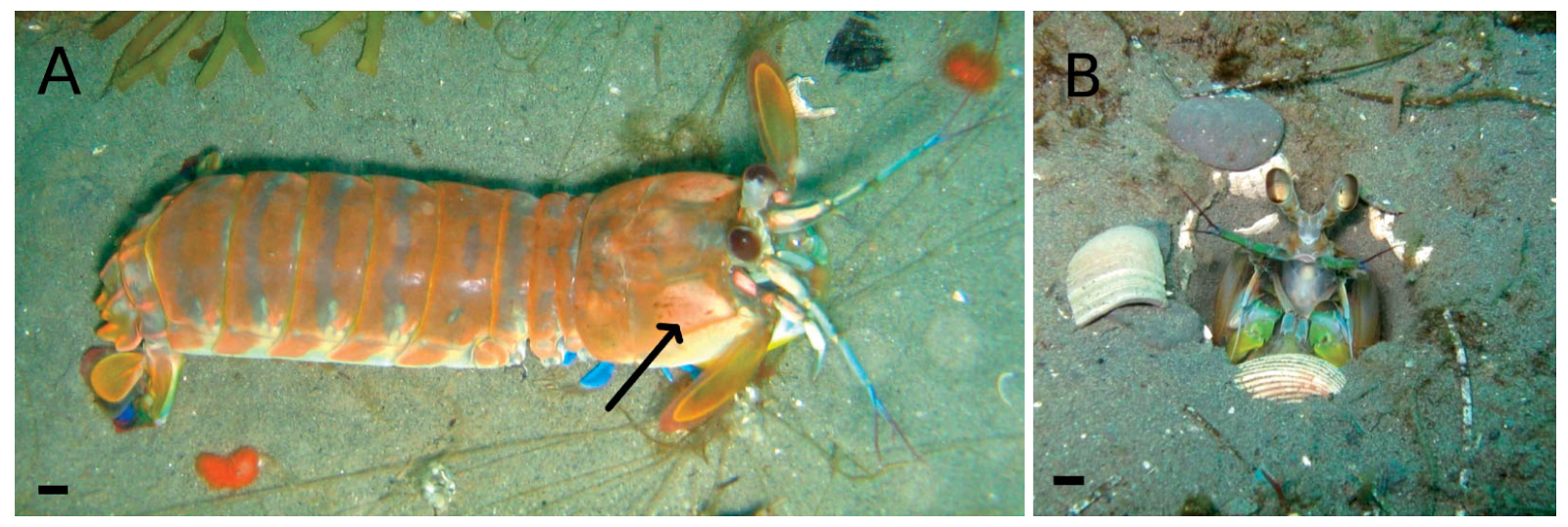

Fig. 1. Hemisquilla californiensis is a large mantis shrimp that builds burrows in the muddy benthic zone off the coast of southern California. (A) Individuals regularly leave their burrows to forage and interact with neighboring mantis shrimp. Males possess red patches on either side of the carapace, which lie just above the sound-producing muscles (arrow). (B) Individuals can often be seen guarding their burrows. During the mating season, males decorate the edges of their burrows with shells, presumably to attract females (J. Engle pers. comm.). Scale bar: $\sim 1 \mathrm{~cm}$ 
season (March 2009 and March 2010). We deployed each recording device using SCUBA and anchored it to the substrate near an $H$. californiensis burrow $(\sim 12$ to $18 \mathrm{~m}$ depth, $13^{\circ} \mathrm{C}$ temperature, 33 salinity). During both field seasons, sunrise was at $\sim 06: 45 \mathrm{~h}$ and sunset was at $\sim 19: 15 \mathrm{~h}$.

Identifying and characterizing rumbles generated in situ. To test whether rumbles in the field differed from those produced in previous laboratory experiments (Patek \& Caldwell 2006), we first identified and described rumbles produced by Hemisquilla californiensis. Sounds were recorded at a total of 4 burrows over the course of 4 dives in the waters near Two Harbors, Santa Catalina Island. Two recording systems were used: a hydrophone that was connected to an underwater video camera (HTI-94-SSQ series, High Tech; sensitivity: $-167.4 \mathrm{~dB}$ re: $1 \mathrm{~V} \mathrm{PPa}^{-1}$, frequency response: 2 to $30 \mathrm{kHz}$; camera: DCR-VX2100, Sony Electronics; housing: VH-2100, Amphibico) and another hydrophone that recorded onto a digital audio recorder (Type 8104 hydrophone, Brüel and Kjaer; sensitivity: $-207.9 \mathrm{~dB}$ re: $1 \mathrm{~V} \mu \mathrm{Pa}^{-1}$, frequency range: 0.1 to $10 \mathrm{kHz}$; recorder: PMD670, Marantz; 16 bit, 48 kHz sample rate). We positioned the recording systems $\sim 30 \mathrm{~cm}$ from the nearest burrow, and we left the area once the equipment was in place to minimize potential interference on the recordings from SCUBA bubbles.

Waveforms and spectrograms of these recordings were used to identify individual rumbles for analysis. For the video files, the audio component was first extracted into a 2-channel clip (iMovie 4.0.1, Apple; $16 \mathrm{bit}, 48 \mathrm{kHz}$ sample rate). Then each file from the 4 dives was downsampled to $2000 \mathrm{~Hz}$ (Matlab v. 2007b, The Mathworks) and low-pass filtered at $500 \mathrm{~Hz}$ (Raven Pro 1.4, Cornell Lab of Ornithology, Ithaca, NY). The following spectrogram parameters were used to view and analyze these recordings: for the files from the first recording system - Hann window, 8192 Pt. fast Fourier transform (FFT), 90\% overlap (yielding a frequency resolution of $0.244 \mathrm{~Hz}$ ); for files from the other recording system-Hann window, 16384 Pt. FFT, 90 \% overlap (yielding a frequency resolution of $0.122 \mathrm{~Hz}$ ). For each rumble, we measured duration, lowest frequency, highest frequency, dominant frequency (the frequency, in $\mathrm{Hz}$, with the highest sound level), and peak power (the sound level, in relative $\mathrm{dB}$, at the dominant frequency). For the data from the recording units described above, we report the average for the dominant frequency and duration. However, these hydrophones were not calibrated, so for peak power, we report relative levels and limit our comparisons to data from the same recordings.

The field recordings revealed rumbles that were produced in groups of 2, 3, or 4 . Therefore, we introduced the term 'rumble group' to describe a short series of rumbles (e.g. Fig. 2) that have similar dominant frequency and peak power and occur within $0.25 \mathrm{~s}$ of each other. Rumble groups were usually produced in long repetitive series, lasting from several minutes to hours, which we call 'rumble bouts' (Fig. 3). In order to define the structure of a typical rumble group, we used data from multiple rumble bouts, which were recorded on different days and at different locations (and were assumed to be independent; Figs. 2 \& 3). We analyzed bouts which had at least 9 rumble groups with at least 2 rumbles per group (minimum $\mathrm{df}=8$ ), allowing us to make 17 comparisons. Matched pairs $t$-tests were used to examine the differences in peak power and duration between the first and second rumble of each group (JMP v. 7.0, SAS Institute).

Within certain recording periods, we observed acoustically distinct rumble bouts which either alternated or overlapped temporally. To test whether these varying rumble bouts could have been produced by different individuals, we examined their dominant frequency (which could differ due to a physical quality such as body size) and relative peak power (which could differ due to body size and distance from the hydrophone). We assigned labels to distinct rumble bouts (i.e. Bout A, Bout B, etc. as in Fig. 3) and tested for significant differences in dominant frequency and peak power using Kruskal-Wallis test (JMP, SAS). Because the first rumble of each group was typically the most consistent, we only compared these.

Locating the source of mantis shrimp rumbles. In order to confirm that rumbles originated from mantis shrimp burrows and not another unidentified source, we deployed a 3-element hydrophone array to localize the source of the sounds (array engineered by the Cornell Lab of Ornithology; 3 HTI-94-SSQ hydrophones, High-Tech; sensitivities: -169.4, -169.4, -169.2 dB re: $1 \mathrm{~V} \mu \mathrm{Pa}^{-1}$, frequency response: 2 to $30 \mathrm{kHz}$ ). We

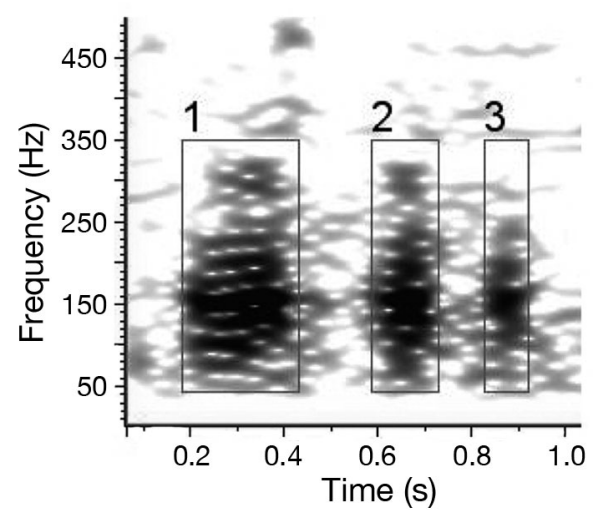

Fig. 2. Hemisquilla californiensis. Typical rumble group, consisting of 3 rumbles (labeled 1, 2, and 3). Spectrogram parameters: Hann window, 256 samples; 3 dB filter bandwidth, $11.2 \mathrm{~Hz}$; discrete Fourier transform (DFT), 8192 samples; overlap, $90 \%$; 50 to $500 \mathrm{~Hz}$ bandpass filter 


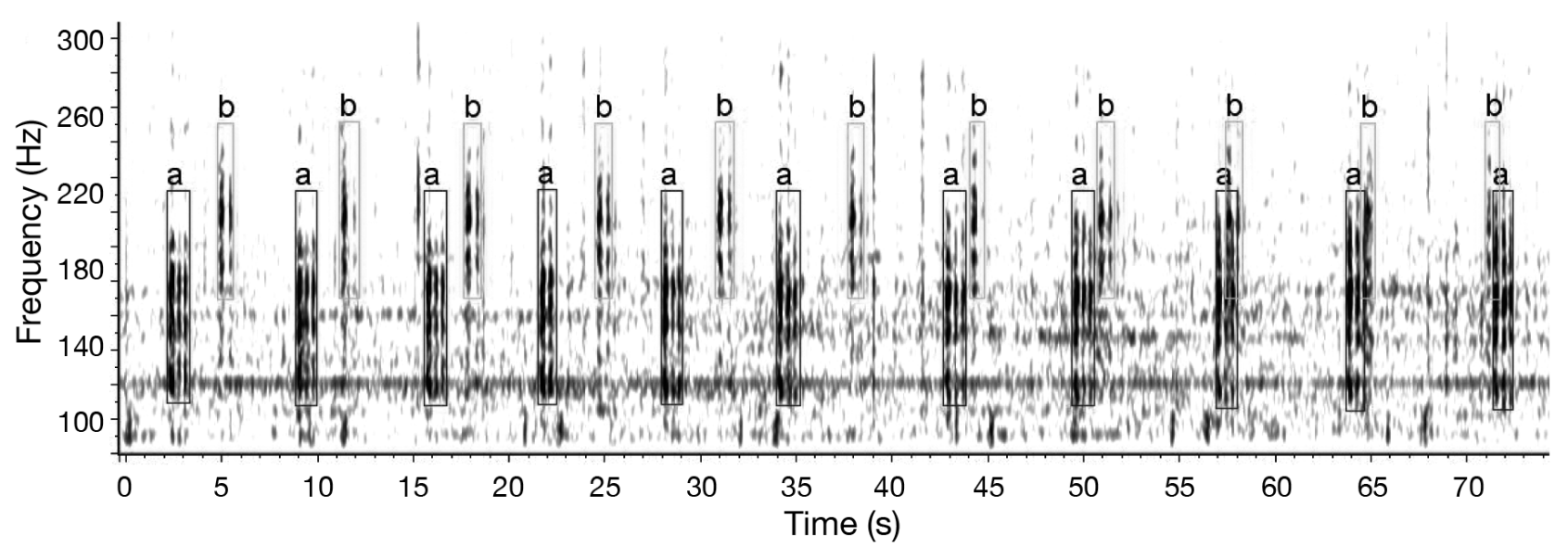

Fig. 3. Hemisquilla californiensis. Rumble groups alternated and sometimes overlapped, suggesting that multiple individuals were producing the sounds. The spectrogram shows 2 rumble bouts (labeled a and b); these data correspond to example no. 11 in Table 1 and data presented in Fig. 4. Boxes surround rumble groups, not individual rumbles. Spectrogram parameters: Hann window, 256 samples; 3 dB filter bandwidth, $5.62 \mathrm{~Hz}$; DFT, 1024 samples; overlap, $90 \%$; 50 to $500 \mathrm{~Hz}$ bandpass filter

identified a focal male and its burrow at a depth of $14 \mathrm{~m}$ by SCUBA diving. We placed the hydrophones in an equilateral triangle $\left(5 \mathrm{~m} \mathrm{side}^{-1}\right)$ centered around the burrow, and recorded sounds between 25 to 28 March 2010. Hydrophone cables were extended to the surface and into a boat where sounds were recorded on a computer with Raven Pro software, with a sample rate of either 5 or $20 \mathrm{kHz}$ and a sensitivity range of either \pm 0.5 or $\pm 5 \mathrm{~V}$ (16 bit, NIDAQ USB-6251, National Instruments).

Although we recorded sounds for several hours, we only analyzed a small subset of rumbles that were free of boat noise and/or other obscuring sounds. For the analysis, all data were bandpass filtered (10 to $500 \mathrm{~Hz}$ ). We used the XBAT software program (www.xbat.org; Figueroa 2005) to compute multi-channel spectrograms (Hanning window, 2214 or 512 Pt. FFT depending on sample rate of file), visually and aurally confirm the occurrences of rumbles, and annotate individual rumbles. A second customized Matlab-based program was used to compute the location of rumbles based on their times of occurrence at each of the 3 hydrophones (Clark et al. 1996, Clark \& Ellison 2000). To assure correct localization, we limited our analysis to rumbles with waveforms that could be clearly observed on all 3 channels.

Identifying patterns in mantis shrimp acoustic activity and vessel noise. To test whether patterns in mantis shrimp acoustic activity matched previously documented behavioral activity (Basch \& Engle 1989), we deployed an autonomous recording unit for almost 8 d, from 21 March at 16:20 h until 29 March 2009 at 10:30 h (Cornell Lab of Ornithology; HTI-90-U hydrophone, High-Tech; sensitivity: $-197.3 \mathrm{~dB}$ re: $1 \mathrm{~V} \mu \mathrm{Pa}^{-1}$, frequency response: 2 to $20 \mathrm{kHz}$, continuous sampling at 16 bit, $32 \mathrm{kHz}$ sample rate). The unit was deployed $\sim 9 \mathrm{~km}$ from the Two Harbors site and anchored $3.8 \mathrm{~m}$ from the nearest male Hemisquilla californiensis burrow at $18 \mathrm{~m}$ depth.

In order to examine patterns across each day, acoustic data were downsampled to $1000 \mathrm{~Hz}$ and combined to create $24 \mathrm{~h}$ files. These were converted into daily spectrograms, and each day of data was visually and aurally analyzed by the same trained investigator to identify rumble patterns and boat noise. We established operational definitions to describe whether these rumble rates should be considered 'rhythmic' (occurring in groups, <0.25 s apart, as defined above) or 'sporadic' (occurring as single rumbles). Power spectral density distribution levels ( $\mathrm{dB}$ re: $1 \mathrm{\mu Pa}^{2} \mathrm{~Hz}^{-1}$ ) and sound levels ( $\mathrm{dB}$ re:1 $\mu \mathrm{Pa}$ ) were computed based on hydrophone sensitivities and gain settings of the recording systems.

\section{RESULTS}

Rumble characteristics. Rumbles measured at different burrows and on different days had similar acoustic features, but exhibited high variability in dominant frequency. For all rumbles, we measured an average dominant frequency of $167.0 \mathrm{~Hz}( \pm 0.66 \mathrm{SE}$, range 53 to $257 \mathrm{~Hz})$ and an average duration of $0.20 \mathrm{~s}( \pm 0.0013 \mathrm{SE}$, range 0.06 to $0.6 \mathrm{~s}$ ). The initial rumble in a group had significantly higher relative sound levels than the second rumble in 16 out of 17 comparisons made (average difference $=5.1 \mathrm{~dB}$, average $\mathrm{SE}=0.71$, matched pairs $t$ tests, $\mathrm{p}<0.01$ for all tests). The first rumble was also significantly longer in duration than the second rumble in 14 out of 17 comparisons (average difference $=0.092$ $\mathrm{s}$, average $\mathrm{SE}=0.015$, matched pairs $t$-tests, $\mathrm{p}<0.01$ for all tests). 
Table 1. Hemisquilla californiensis. Tests performed from recordings collected at 12 distinct days and times. Within each test, 2 temporally overlapping and acoustically distinct bouts were identified. For each bout, the number of rumble groups tested (RG), mean number of rumbles per group $\left(\mathrm{R} \mathrm{G}^{-1}\right)$, dominant frequency $\left(\mathrm{F}_{\mathrm{Dom} i} \mathrm{~Hz} \pm \mathrm{SE}\right)$, and relative peak power $\left(\mathrm{P}_{\text {Peaki }}\right.$ relative $\left.\mathrm{dB} \pm \mathrm{SE}\right)$ are shown, as well as the differences in dominant frequency $\left(\mathrm{F}_{\text {Diff }} \mathrm{Hz}\right)$ and peak power $\left(\mathrm{P}_{\text {Diff; }}\right.$ relative $\left.\mathrm{dB}\right)$. Kruskal-Wallis tests were used to compare the dominant frequency and peak power between Bouts A and B, using only the first rumble of each group; bold: statistically significant comparisons

\begin{tabular}{|c|c|c|c|c|c|c|c|c|c|c|c|c|c|c|}
\hline \multirow[b]{2}{*}{ Test } & \multicolumn{4}{|c|}{$\longrightarrow$ Bout $\mathrm{A}-$} & \multicolumn{4}{|c|}{$\longrightarrow$ Bout B } & \multicolumn{6}{|c|}{-Comparisons } \\
\hline & No. of RGs & $\mathrm{R} \mathrm{G}^{-1}$ & $\mathrm{~F}_{\mathrm{Dom}}(\mathrm{Hz})$ & $\mathrm{P}_{\text {Peak }}(\mathrm{dB})$ & No. of RGs & $\mathrm{R} \mathrm{G}^{-1}$ & $\mathrm{~F}_{\mathrm{Dom}}(\mathrm{Hz})$ & $\mathrm{P}_{\text {Peak }}(\mathrm{dB})$ & $F_{\text {Diff }}$ & $H$ & $\mathrm{p}$ & $\mathrm{P}_{\text {Diff }}$ & $H$ & $\mathrm{p}$ \\
\hline 1 & 22 & 4 & $197.2 \pm 1.0$ & $70.8 \pm 0.19$ & 11 & 3 & $230.1 \pm 9.62$ & $62.1 \pm 0.60$ & 33.0 & 8.0 & 0.005 & 8.7 & 21.4 & 0.0001 \\
\hline 2 & 8 & 3 & $205.5 \pm 0.95$ & $70.8 \pm 0.25$ & 6 & 1 & $148.5 \pm 1.76$ & $76.6 \pm 0.41$ & 57.1 & 9.7 & 0.002 & 5.8 & 9.6 & 0.0002 \\
\hline 3 & 15 & 4 & $169.5 \pm 4.4$ & $83.2 \pm 0.26$ & 15 & 2 & $143.7 \pm 0.49$ & $92.1 \pm 0.59$ & 25.8 & 21.8 & 0.0001 & 8.9 & 21.8 & 0.0001 \\
\hline 4 & 12 & 4 & $140.9 \pm 0.49$ & $71.1 \pm 1.10$ & 7 & 2 & $207.9 \pm 2.31$ & $69.0 \pm 1.13$ & 66.9 & 12.6 & 0.0004 & 2.1 & 1.8 & 0.176 \\
\hline 5 & 13 & 4 & $132.9 \pm 0.58$ & $91.9 \pm 0.19$ & 8 & 2 & $185.8 \pm 3.08$ & $82.5 \pm 0.81$ & 52.9 & 14.2 & 0.0002 & 9.4 & 14.2 & 0.0002 \\
\hline 6 & 24 & 2 & $163.1 \pm 0.86$ & $70.7 \pm 0.29$ & 24 & 3 & $141.8 \pm 5.18$ & $68.8 \pm 0.22$ & 21.3 & 7.5 & 0.006 & 2.0 & 19.4 & 0.0001 \\
\hline 7 & 17 & 3 & $145.1 \pm 0.92$ & $71.3 \pm 0.46$ & 16 & 1 & $135.5 \pm 7.05$ & $64.5 \pm 2.1$ & 9.6 & 3.4 & 0.065 & 6.8 & 23.3 & 0.0001 \\
\hline 8 & 13 & 3 & $144.7 \pm 2.97$ & $73.5 \pm 0.44$ & 8 & 1 & $184.5 \pm 0.99$ & $66.2 \pm 0.42$ & 39.9 & 14.5 & 0.0001 & 7.3 & 14.2 & 0.0002 \\
\hline 9 & 19 & 3 & $119.4 \pm 1.54$ & $74.3 \pm 0.18$ & 13 & 3 & $163.6 \pm 3.36$ & $70.9 \pm 0.39$ & 44.2 & 23.5 & 0.0001 & 3.3 & 18.4 & 0.0001 \\
\hline 10 & 17 & 2 & $171.5 \pm 2.28$ & $72.3 \pm 0.34$ & 22 & 3 & $149.2 \pm 1.19$ & $71.8 \pm 0.34$ & 22.3 & 24.9 & 0.0001 & 0.51 & 0.54 & 0.46 \\
\hline 11 & 13 & 3 & $167.7 \pm 3.38$ & $66.5 \pm 0.47$ & 15 & 1 & $213.4 \pm 4.08$ & $59.9 \pm 0.59$ & 45.8 & 19.3 & 0.0001 & 6.5 & 19.7 & 0.0001 \\
\hline 12 & 38 & 1 & $164.7 \pm 0.34$ & $74.3 \pm 0.019$ & 26 & 2 & $178.9 \pm 0.69$ & $64.5 \pm 0.37$ & 14.1 & 47.0 & 0.0001 & 9.8 & 45.6 & 0.0001 \\
\hline
\end{tabular}

Differences between overlapping rumble groups. We found 12 examples (from different days and recordings) in which co-occurring rumble bouts differed in either dominant frequency or relative peak power of the rumbles (Table 1). We found 9 examples in which both the dominant frequency and the peak power differed significantly (Fig. 4) between the 2 bouts. In several cases, rumbles overlapped temporally (see example in Fig. 3).

Locations of mantis shrimp rumbles. We estimated the location of 52 rumbles (Fig. 5). The locations were clustered; some rumbles originated from inside the hydrophone triangle, closest to No. 3, while others originated outside the triangle (Fig. 5). In a few cases,

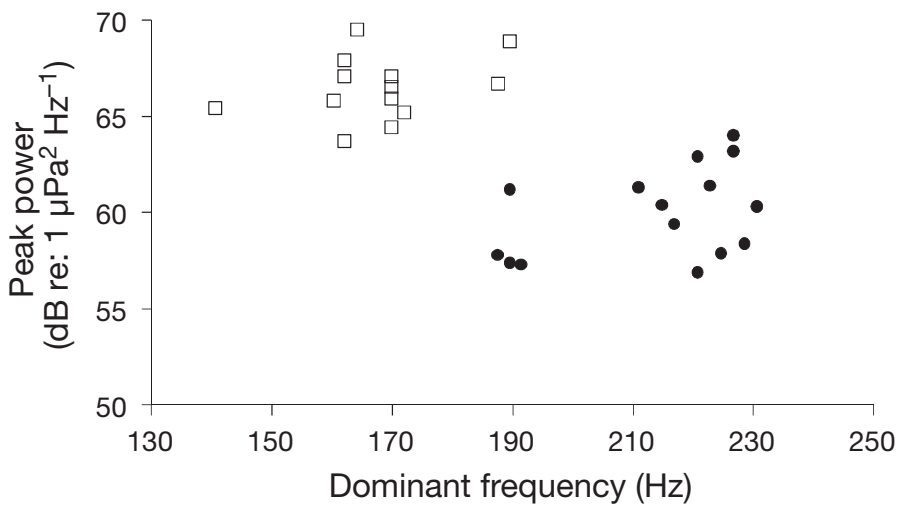

Fig. 4. Hemisquilla californiensis. Although relative peak power ( $\mathrm{dB}$ re: $1 \mathrm{\mu Pa}^{2} \mathrm{~Hz}^{-1}$ ) and dominant frequency (Hz) were not correlated, 2 bouts of rumble groups showed distinct clusters for these 2 parameters (Series A = open square, Series B = filled circle). Each point represents data from the first rumble of each of the rumble groups analyzed (for $A, n=13$; for $B, n=$ 15). These data correspond to example no. 11 in Table 1 and the spectrogram shown in Fig. 3 rumbles that were $<2 \mathrm{~s}$ apart originated from locations that were several meters apart.

Diel patterns in mantis shrimp acoustic activity. At the site of the autonomous recording unit, we observed daily patterns in mantis shrimp acoustic activity (Table 2). Every morning and on 7 of 8 evenings ( 17:00 to $19: 30 \mathrm{~h})$, we detected loud rhythmic rumble groups. At night (19:30 to 05:30 h), we observed sounds that closely resembled mantis shrimp rumbles but were less rhythmic; these rumbles occurred in isolation and were of lower received level and lower frequency than the more intensive and clearly discernible daytime rumbles. At mid-day ( 11:30 to 01:30 h), we did not detect rumbles in 6 of $7 \mathrm{~d}$, but periods without rumbles were more variable, and the compounding effect of vessel noise made it difficult to discern patterns.

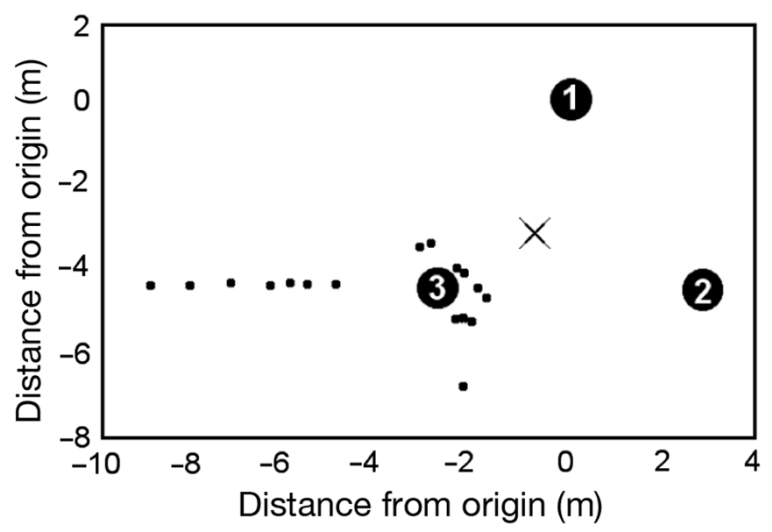

Fig. 5. Hemisquilla californiensis. Localization of rumbles using a 3-hydrophone array (black numbered circles) demonstrated that the sounds were emitted in close vicinity to the array, but not from the burrow opening $(\times)$; small dots: most likely location for each rumble, as calculated by a time-delay algorithm. Hydrophone no. 1 was used as the origin $(0,0)$ for the grid in the time-delay algorithm 
Table 2. Hemisquilla californiensis. Daily patterns in acoustic activity were consistent with published data on behavioral activity and burrow openings (data on open burrows from Basch \& Engle 1989, their Fig. 3; $\mathrm{n}=13$ ind.). Sounds were recorded for almost 8 continuous days, but one mid-day period was missed

\begin{tabular}{|lcccc|}
\hline Period & Time of day & Acoustic activity & $\begin{array}{c}\text { No. of days } \\
\text { observed }\end{array}$ & $\begin{array}{c}\text { Open burrows } \\
(\%)\end{array}$ \\
\hline Morning crepuscular period & $\sim 06: 30-08: 30 \mathrm{~h}$ & Loud, rhythmic rumbles & 8 of 8 & 50 \\
Mid-morning & $\sim 09: 30-11: 30 \mathrm{~h}$ & Loud, rhythmic rumbles & 6 of 8 & nd \\
Mid-day & $\sim 11: 30-01: 30 \mathrm{~h}$ & No rumbling & 6 of 7 & 15 \\
Evening crepuscular period & $\sim 17: 00-19: 30 \mathrm{~h}$ & Loud, rhythmic rumbles & 7 & $50-70$ \\
Night & $\sim 20: 00-05: 30 \mathrm{~h}$ & Quiet, sporadic, low-frequency rumbles & 8 of 8 & 0 \\
\hline
\end{tabular}

\section{DISCUSSION}

Compared to the relatively uniform sounds previously recorded in the laboratory (Patek \& Caldwell 2006), the field-based recordings were more variable in their frequency and temporal characteristics. Patterns of acoustic activity matched previously published patterns of behavioral activity (Basch \& Engle 1989). The timing of distinct rumble patterns, coupled with results from the hydrophone array, suggest that multiple individuals in an area produce sound simultaneously, possibly in a coordinated behavioral system. The power spectral density distribution of mantis shrimp rumbles was different from the background noise (Fig. 6), suggesting that these sounds make a substantial contribution to the benthic soundscape.

\section{Characteristics of rumbles from the field}

The most distinct difference between tank and field recordings was that rumbles in the field were produced in rhythmic groups. Across all recording types and days, certain parameters of rumble groups were conserved: the first rumble was the longest and loudest rumble of the group, and rumbles typically occurred

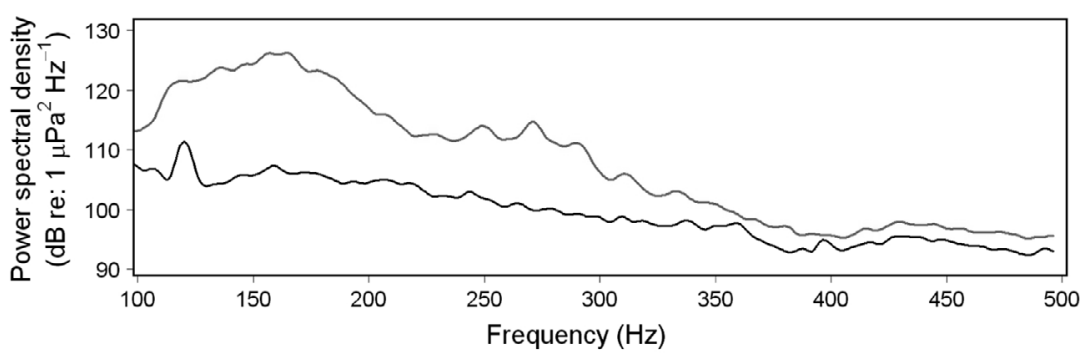

Fig. 6. Hemisquilla californiensis. Power spectral density measurements of mantis shrimp rumbles (grey line) were greater than background noise (black line) across the 100 to $500 \mathrm{~Hz}$ frequency band, but especially in the main communication band ( 100 to $250 \mathrm{~Hz}$ ). The peak in background noise at $120 \mathrm{~Hz}$ was from the autonomous recording unit's hard drive within a limited frequency band. However, the dominant frequency, relative peak power, and number of rumbles per group were significantly different across sampling days but also within sampling periods, suggesting that different individuals produced acoustically distinct rumbles. These results corroborate the findings of the laboratory experiment, which demonstrated variability between rumbles from different individuals (Patek \& Caldwell 2006). Furthermore, our field data revealed recording periods in which different rumble groups overlapped temporally (Fig. 3). It seems unlikely that the 2 sound-producing muscles within 1 mantis shrimp could simultaneously produce 2 rumbles that differed in both dominant frequency and power. These results led us to conclude that several mantis shrimp within the vicinity of the hydrophone were generating rumbles simultaneously. Indeed, our hydrophone array located multiple sources of rumbles, which were several meters apart (Fig. 5). Although we cannot rule out the possibility that our focal animal was moving around while producing sound, examples of rumbles occurring $<2 \mathrm{~s}$ apart at different locations provide strong evidence that 2 ind. were rumbling. Furthermore, there were many periods in which $>2$ mantis shrimp were audible, creating a cluttered spectrogram and perhaps representing a mantis shrimp 'chorus' (Fig. 7).

The other differences between field and laboratory recorded rumbles (Patek \& Caldwell 2006) were primarily due to differences in methodology and sampling environments. For example, in the tank experiment, individuals were approached by a hydrophone or a stick; these animals probably produced sounds in an antipredator context (Bradbury \& Vehrencamp 1998, Patek \& Caldwell 2006, Staaterman et al. 2010). Furthermore, tank recordings typically distort the acoustic quality of animal sounds (Parvulescu 1967, Akamatsu et al. 2002, Patek et al. 2009). 


\section{Diel patterns in mantis shrimp acoustic activity}

The daily patterns in acoustic activity were consistent with those described by Basch \& Engle (1989). During crepuscular periods, individuals can be observed on foraging expeditions or guarding the entrance to their burrows (E. Staaterman pers. obs.). Acoustic activity was high during these times and rumbles were produced in groups. During periods of bright daylight and at night, Hemisquilla californiensis close their burrow with a mucous cap (Table 2; Basch \& Engle 1989, 1993). Sporadic, lower-frequency, and relatively lower level sounds were recorded during these times. Differences in acoustic characteristics might result from the mucous plug covering the burrows or from the location of the animals within their burrows.

\section{Acoustic ecology of Hemisquilla californiensis}

The rhythmic nature of the daytime rumbles, and the variability in rumble characteristics for simultaneous rumble bouts, suggest that the rumbles serve a conspecific, communicative function (Bradbury \& Vehrencamp 1998).

Many crustaceans are capable of detecting sound through a variety of mechanisms, including sensory hairs which function as particle motion detectors for both water-borne and substrate-borne signals (Breithaupt \& Tautz 1990, Budelmann 1992, Taylor \& Patek 2010). Like most crustaceans, Hemisquilla californiensis is covered with sensory hairs and is thus capable of detecting some forms of vibration. Although particle motion is dominant in the near-field region (usually $<1$ wavelength from the sound source), this region is $5 \times$ larger in water than it is in air, making this a behav- iorally feasible range for communication in crustaceans (Ewing 1989). For example, the average mantis shrimp rumble with a dominant frequency of $167 \mathrm{~Hz}$, traveling at $1500 \mathrm{~m} \mathrm{~s}^{-1}$ in seawater, would have a nearfield, free-field range of $\sim 9 \mathrm{~m}$. Given the measured population density of $H$. californiensis of 1 ind. per $12 \mathrm{~m}^{2}$ (Basch \& Engle 1993), mantis shrimp could detect rumbles from their neighbors. In addition, substrate-borne vibrations could further enhance signal detectability.

Why do individuals produce acoustically distinct rumbles? To address this question, we should consider the behavioral activity that occurs during the early mating season, when our recordings were collected. At all times of the year, this species is considered to be highly territorial and the spacing of burrows plays an important role in its ecology (Basch \& Engle 1989, Basch \& Engle 1993). During the mating season, males decorate their burrows with shells (Fig. 1) and recruit females to their burrows. Burrows are guarded especially intensely at this time, as intruder males have been seen evicting resident males in order to gain access to females (J. Engle pers. comm.). Therefore, we present 2 non mutually exclusive potential functions of the rumble: (1) maintenance of territory, and (2) attraction of mates.

Given the spacing of the burrows and the presumed range at which rumbles are detectable, this may be a communication network in which a sender's signal is detected by multiple neighbors (McGregor 1993, 2005). In this case, acoustic signals may function to help individuals establish and maintain territories, as observed in other taxa (reviewed by McGregor 1993). For example, field crickets respond differently to loudspeakers playing highly degraded versus less degraded sounds of conspecifics, indicating that the quality of the sound helps crickets to determine the

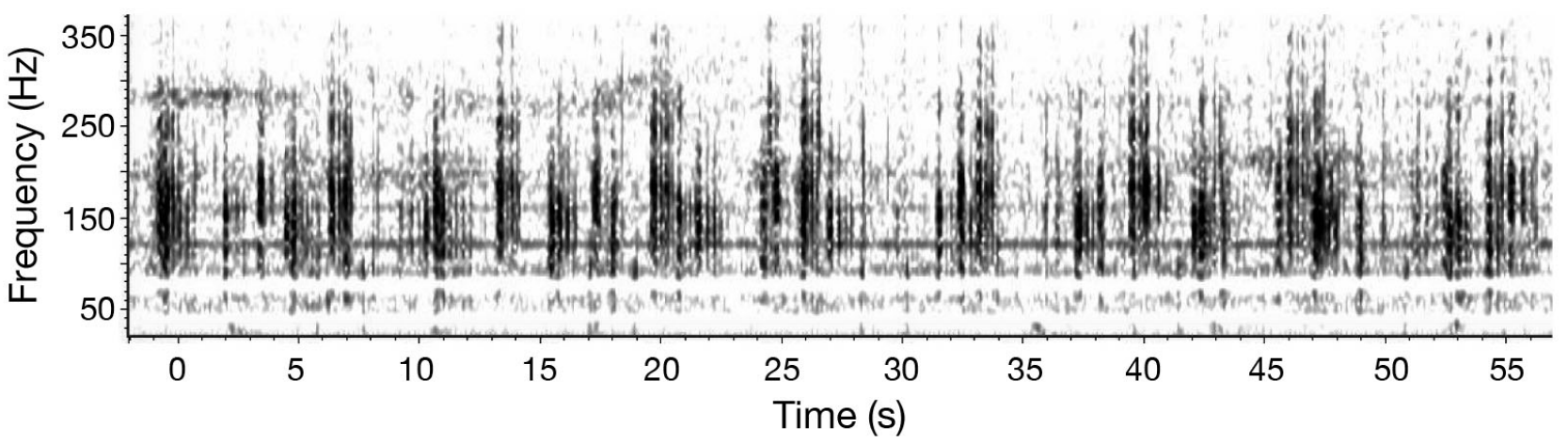

Fig. 7. Hemisquilla californiensis. Rumble groups from multiple individuals are visible in the spectrogram; note the differences in temporal patterning, intensity (as indicated by display darkness), and frequency. Some repetitive rumble groups are visible, but there is so much acoustic activity that it is difficult to discern exactly how many individuals are signaling. Sounds from the autonomous recording unit's hard drive have been filtered out, except for the $120 \mathrm{~Hz}$ 'hum' (horizontal line). Spectrogram parameters: Hann window, 256 samples; 3 dB filter bandwidth, 5.62 Hz; DFT, 1024 samples; overlap, $90 \%$; bandstop filters at $35 \mathrm{~Hz}$ and $75 \mathrm{~Hz}$ 
distance at which a neighboring individual is signaling. In electric fish, individuals respond less aggressively to signals produced by immediate neighbors than to signals produced by strangers. These 2 examples show that, in other taxa, the ability to distinguish the distance and identity of signaling conspecifics helps individuals determine the appropriate aggression levels with which to defend their territories (McGregor 1993). If mantis shrimp produce rumbles while exploring regions outside of their burrows, burrow residents would probably be able to detect movement of their neighbors (potential intruders) and use this information to respond appropriately. During one of the hydrophone array deployment dives, we observed a neighboring male shrimp near the burrow of our focal male (E. Staaterman \& A. Gallagher pers. obs.). The data from the array revealed that there were 2 sound-producing individuals in the vicinity of the array. This neighboring male was probably the second individual that was detected on the array recordings, and these 2 individuals were perhaps using acoustic signals to maintain their territories.

The fact that only males produced this sound in the laboratory (Patek \& Caldwell 2006), suggests another possible function of the rumbles: female attraction. A single male can recruit up to 2 females into its burrow (J. Engle pers. comm.). In the communication network of tree frogs, males use acoustic signals to attract females, and deliberately partition the acoustic space by adjusting either their temporal patterning or frequency (Grafe 2005). The considerable variability in temporal patterning and dominant frequencies observed in mantis shrimp rumbles makes this function highly possible. Furthermore, the differences in the dominant frequency, number of rumbles per group, and peak received level may convey important information to females about a male's reproductive status. For example, in a study on fiddler crabs, females showed preferences for certain characteristics of visual signals sent by males within a chorus, and males adapted their signals depending on the signaling behavior of neighboring males (Burford et al. 1998).

\section{CONCLUSIONS}

Our results demonstrate evidence of mantis shrimp 'chorusing,' in which multiple individuals produce sounds simultaneously. The prevalence of rumbles suggests that these sounds evolved to serve a critical function in their ecology. Increasing levels of lowfrequency anthropogenic noise (Southall 2009) may mask these communication sounds as well as those from myriad undiscovered and under-represented benthic invertebrates.
Acknowledgements. We thank J. Engle and R. L. Caldwell for stimulating discussions. This work would not have been possible without the logistical and technical support of the staff at the Cornell Laboratory of Ornithology, specifically I. Urazghildiiev, P. Marchetto, A. Warde, A. Rice, and D. Hawthorne; and the Wrigley Institute for Environmental Studies, specifically T. Oudin, G. Smith, and L. Czarnecki. This research was supported by a National Science Foundation Integrative Organismal Systems grant (\#1014573 to S.N.P.) and a Radcliffe Fellowship (to S.N.P.).

\section{LITERATURE CITED}

Akamatsu T, Okumura T, Novarini N, Yan H (2002) Empirical refinements applicable to the recording of fish sounds in small tanks. J Acoust Soc Am 112:3073-3082

Alcock A (1900) A naturalist in Indian seas. J. Murray, London

$\mathrm{Au}$ WWL, Banks K (1998) The acoustics of the snapping shrimp Synalpheus parneomeris in Kaneohe Bay. J Acoust Soc Am 103:41-47

Balss H (1921) Über Stridulationsorgane bei dekapoden Crustaceen. Natwiss Wochenschr 20:697-701

Basch LV, Engle JM (1989) Aspects of the ecology and behavior of the stomatopod Hemisquilla ensigera californiensis (Gonodactyloidea: Hemisquillidae). In: Ferrero EA (ed) Biology of stomatopods. Mucchi, Modena

Basch LV, Engle JM (1993) Biogeography of Hemisquilla ensigera californiensis (Crustacea: Stomatopoda) with emphasis on Southern California bight populations. In: Hochberg FG (ed) Third California Islands Symposium. Santa Barbara Museum of Natural History, Santa Barbara, p 211-220

Bradbury JW, Vehrencamp SL (1998) Principles of animal communication. Sinauer Associates, Sunderland, MA

Breithaupt T, Tautz J (1990) The sensitivity of crayfish mechanoreceptors to hydrodynamic and acoustic stimuli. In: Wiese K, Krenz WD, Tautz J, Reichert H, Mulloney B (eds) Frontiers in crustacean neurobiology. Birkhauser Verlag, Basel, p 115-120

Brooks WK (1886) Report on the Stomatopoda collected by H.M.S. Challenger during the years 1873-1876. Neill, London

Budelmann BU (1992) Hearing in Crustacea. In: Webster DB, Fay RR, Popper AN (eds) The evolutionary biology of hearing. Springer-Verlag, New York, p 131-139

Burford FRL, McGregor PK, Oliviera RF (1998) Chorusing by male European fiddler crabs, Uca tangeri: a study of visual communication networks. Acta Ethol 1:33-41

Caldwell RL (1979) Cavity occupation and defensive behaviour in the stomatopod Gonodactylus festae: evidence for chemically mediated individual recognition. Anim Behav 27:194-201

> Clark CW, Ellison WT (2000) Calibration and comparison of the acoustic location methods used during the spring migration of the bowhead whale, Balaena mysticetus, off Pt. Barrow, Alaska, 1984-1993. J Acoust Soc Am 107: 3509-3517

Clark CW, Charif R, Mitchell S, Colby J (1996) Distribution and behavior of the bowhead whale, Balaena mysticetus, based on the analysis of acoustic data collected during the 1993 spring migration off Point Barrow, Alaska. Rep Int Whaling Comm 46:541-552

Cronin TW, Marshall J (2004) The unique visual world of mantis shrimps. In: Prette FR (ed) Complex worlds from simpler nervous systems. MIT Press, Cambridge, MA, p 239-268 
Dumortier B (1963) Morphology of sound emission apparatus in Arthropoda. In: Busnel RG (ed) Acoustic behaviour of animals. Elsevier, New York, p 277-345

Ewing AW (1989) Arthropod bioacoustics: neurobiology and behaviour. Cornell University Press, Ithaca

Figueroa H (2005) Acoustic tool development with XBAT. 2nd Int Workshop on Detection and Localization of Marine Mammals Using Passive Acoustics, Monaco, France, p 53

Giesbrecht W (1910) Stomatopoden. Friedländer \& Sohn, Berlin

Grafe TU (2005) Anuran choruses as communication networks. In: McGregor PK (ed) Animal communication networks. Cambridge University Press, Cambridge

Gray AE, Mulligan TJ, Hannah R (1997) Food habits, occurrence, and population structure of the bat ray, Myliobatis californica, in Humboldt Bay, California. Environ Biol Fishes 49:227-238

Haderlie EC, Abbott DP, Caldwell RL (1980) Three other crustaceans: a copepod, a leptostracan, and a stomatopod. In: Morris RH, Abbott DP, Haderlie EC (eds) Intertidal invertebrates of California. Stanford University Press, Stanford, CA, p 631-635

Hazlett BA, Winn HE (1962) Sound production and associated behavior of Bermuda crustaceans (Palinurus, Gonodactylus, Alpheus, Synalpheus). Crustaceana 4:25-38

Henninger HP, Watson WH III (2005) Mechanisms underlying the production of carapace vibrations and associated waterborne sounds in the American lobster, Homarus americanus. J Exp Biol 208:3421-3429

Kemp S (1913) An account of the Crustacea Stomatopoda of the Indo-Pacific region. Mem Indian Mus 4:1-217

Lammers MO, Brainard RE, Au WWL, Mooney TA, Wong KB (2008) An ecological acoustic recorder (EAR) for long-term monitoring of biological and anthropogenic sounds on coral reefs and other marine habitats. J Acoust Soc Am 123:1720-1728

Locascio JV, Mann DA (2008) Diel periodicity of fish sound production in Charlotte Harbor, Florida. Trans Am Fish Soc 137:606-615

McCauley RD, Cato DH (2000) Patterns of fish calling in a nearshore environment in the Great Barrier Reef. Philos Trans R Soc Lond B 355:1289-1293

McGregor PK (1993) Signalling in territorial systems: a con-

Editorial responsibility: Hans Heinrich Janssen, Oldendorf/Luhe, Germany text for individual identification, ranging, and eavesdropping. Philos Trans R Soc Lond, B 340:237-244

McGregor PK (2005) Introduction. In: McGregor PK (ed) Animal communication networks. Cambridge University Press, Cambridge

Parvulescu A (1967) The acoustics of small tanks. In: Tavolga WN (ed) Marine bioacoustics. Pergamon Press, New York, p $7-9$

Patek SN, Caldwell RL (2005) Extreme impact and cavitation forces of a biological hammer: strike forces of the peacock mantis shrimp (Odontodactylus scyllarus). J Exp Biol 208:3655-3664

> Patek SN, Caldwell RL (2006) The stomatopod rumble: sound production in Hemisquilla californiensis. Mar Freshwat Behav Physiol 39:99-111

> Patek SN, Oakley TH (2003) Comparative tests of evolutionary tradeoffs in a palinurid lobster acoustic system. Evolution 57:2082-2100

Patek SN, Korff WL, Caldwell RL (2004) Deadly strike mechanism of a mantis shrimp. Nature 428:819-820

Patek SN, Shipp LE, Staaterman E (2009) The acoustics and acoustic behavior of the California spiny lobster (Panulirus interruptus). J Acoust Soc Am 125:3434-3443

Radford C, Jeffs A, Tindle C, Montgomery JC (2008) Resonating sea urchin skeletons create coastal choruses. Mar Ecol Prog Ser 362:37-43

Southall B, Berkson J, Bowen D, Brake R and others (2009) Addressing the effects of human-generated sound on marine life: an integrated research plan for U.S. federal agencies. Interagency Task Force on Anthropogenic Sound and the Marine Environment, Joint Subcommittee on Ocean Science and Technology, Washington, DC

Staaterman ER, Claverie T, Patek SN (2010) Disentangling defense: the function of spiny lobster sounds. Behaviour 147:235-258

Tavolga WN (1977) Sound production in fishes. Dowden, Hutchinson \& Ross, Stroudsburg, PA

Taylor JRA, Patek SN (2010) Crustacean seismic communication: heard but not present? In: O'Connell-Rodwell CE (ed) The use of vibrations in communication: properties, mechanisms and function across taxa. Research Signpost, Trivandrum, Kerala

Submitted: September 30, 2010; Accepted: June 14, 2011

Proofs received from author(s): July 25, 2011 